\title{
Application of the UIva pertusa bioassay for a toxicity identification evaluation and reduction of effluent from a wastewater treatment plant
}

\author{
Youn-Jung Kim ${ }^{1}$, Young-Seok Han ${ }^{2}$, Eunhee Kim ${ }^{3}$, Jinho Jung ${ }^{4}$, Sang-Hoon Kim ${ }^{5}$, Soon-Joo Yoo ${ }^{5}$, \\ Gi-Sik Shin ${ }^{5}$, Jeong-ju Oh' ${ }^{2}$, Areum Park ${ }^{6}$, Hoon Choi ${ }^{6}$, Mi-Seong Kim ${ }^{6}$, Murray T. Brown ${ }^{7}$ and \\ Taejun Han $^{1,2 *}$
}

${ }^{1}$ Department of Marine Science, Incheon National University, Incheon, South Korea

${ }^{2}$ Green-Pioneer, Incheon, South Korea

${ }^{3}$ Department of Oceanography, Chonnam National University, Gwangju, South Korea

${ }^{4}$ Division of Environmental Science and Ecological Engineering, Korea University, Seoul, South Korea

${ }^{5}$ Department of Water Environment Research, National Institute of Environmental Research, Incheon, South Korea

${ }^{6}$ Department of Life Science, Incheon National University, Incheon, South Korea

7 School of Marine Science and Engineering, Plymouth University, Plymouth, UK

\section{Edited by:}

Ashok Kumar Ghosh, Anugrah Narayan College, Patna, India

Reviewed by:

Hideko Sone, National Institute for Environmental Studies, Japan Namik Mammad Oglu Rashydov, $R$. E. Kavetsky Institute of

Experimental Pathology, Oncology and Radiobiology, Ukraine

*Correspondence:

Taejun Han, Department of Marine Science, Incheon National

University/Green-Pioneer, 119

Academy-ro, Younsu-gu, Incheon

406-772, South Korea

e-mail: hanalgae@hanmail.net
A toxicity identification evaluation (TIE) based on Ulva pertusa spore release was conducted in 3 phases for the identification of the major toxicants in effluent from a wastewater treatment plant (WTP) and the receiving water in an adjacent stream. The toxicity of the final effluent (FE), as compared with raw wastewater, and primary and secondary effluent, showed a greater change over 12-monthly sampling events and appeared to have impacts on the toxicity of the downstream water with a significant correlation $\left(r^{2}=0.89, p<0.01\right)$. In Phase I, toxicity characterization indicated that cations were likely to be the responsible toxicants for the FE. In Phase II, cations such as $\mathrm{Cu}$, $\mathrm{Ni}$, and $\mathrm{Zn}$ were found in the $\mathrm{FE}$ at higher concentrations than the $\mathrm{EC}_{50}$ concentrations determined for the standard corresponding metals. When the concentrations of each metal in the FE samples were plotted against the respective toxicity units, only zinc showed a statistically significant correlation with toxicity $\left(r^{2}=0.86, p<0.01\right)$. In Phase III, using spiking and mass balance approaches, it was confirmed that $\mathrm{Zn}$ was the major toxicant in the effluent from the WTP. Following a change in the Fenton reagent used, to one with a lower Zn content, the toxicity of the FE greatly decreased in subsequent months. The TIE developed here enabled the toxicity of FEs of the WTP to be tracked and for $\mathrm{Zn}$, originating from a reagent used for Fenton treatment, to be successfully identified as the key toxicant. The TIE method based on U. pertusa demonstrated utility as a low cost and simple tool to identify the risk factors for industrial effluents and provided information on regulatory control and management.

Keywords: effluents, TIE, toxicity tests, Ulva pertusa, wastewater treatment

\section{INTRODUCTION}

Wastewater effluents derived from a range of industrial and municipal sources contain mixtures of toxic chemicals that can have deleterious effects on the health of flora and fauna living in the receiving water bodies. These negative impacts can be observed at different levels of biological organization including the individual, population and community, and ultimately can result in alterations to ecosystem functions (Nedeau et al., 2003; Ntengwe and Maseka, 2006). To ensure that the ecological risks posed by these contaminants are fully evaluated effective surveillance strategies need to be established (Bidwell et al., 1998). The most common approach for assessing water quality has been by chemical analyses of source substances and their metabolites. However, it is now generally accepted that there are potential limitations of regulating inputs of effluents and conducting risk assessments based solely on estimates derived from chemical profiling. Routine chemical monitoring alone does not take into account bioavailability, temporal changes in exposure or the interactive effects of pollutants, and the extent of sampling is often limited by cost (Ahlf et al., 2002; Chu and Chow, 2002). To overcome these limitations, complementary bioassay techniques have been developed. Single species toxicity tests can demonstrate causal relationships between the presence of pollutants and adverse effects on biota and these data then used for monitoring and predicting the effects of chemical discharges and deriving chemical-specific water quality guidelines (Ankley et al., 1992). However, while bioassays are useful tools for evaluating toxicity of effluents, such assessments do not provide a logical basis for making appropriate decisions about discharge options. In addition to establishing 
the relative toxicity of the effluent it is necessary to also identify the classes of compounds responsible for the observed toxicity in order to formulate cost-effective reduction and remediation schemes.

In an attempt to address such issues, toxicity identification evaluation (TIE) has been developed by the United States Environmental Protection Agency (USEPA) (US EPA, 1991, 1993a,b) and is now widely used to identify and reduce major toxicants in industrial effluents (Erten-Unal et al., 1998; Jin et al., 1999; Yu et al., 2004; Jo et al., 2008; Park et al., 2008). The TIE methods combine chemical and physical fractionation techniques with the response of the test organism and consist of 3 phases: toxicant characterization (Phase I), toxicant identification (Phase II), and toxicant confirmation (Phase III). In Phase I, the toxicity of each fraction is tested before and after chemical and physical separation in a variety of sequential combinations. In Phase II, chemical analyses of toxic fractions, along with toxicity tests of individual standard toxicants, are conducted and compared to identify and quantify the suspected toxicant(s). In Phase III, a weight-of-evidence approach using chemical spiking and mass balance methodologies is used to determine if the suspected toxicant is the true key toxicant. The TIE approach has been extensively implemented for the analyses of effluents, sludge from industrial wastewater, leachate, and elutriate and pore-water of freshwater and marine sediments (US EPA, 1991, 1993a,b).

Most aquatic species that are used as toxicity test organisms can also be utilized for TIE. For microalgae, the TIE procedure using the unicellular alga Nitzschia closterium was successfully developed and applied to determine the major toxicants in secondary-treated sewage effluent in Australia (Hogan et al., 2005). For macroalgae, a Phase I TIE manipulation was developed to characterize ammonia toxicity in aqueous samples using the green alga Ulva lactuca in the United States (Pelletier et al., 2001). Guidelines for TIEs recommend a range of test organisms, but no complete protocols have been developed with macroalgae, despite their significance as bio-engineers and primary producers in coastal and estuarine waters. A macroalgal toxicity test, based on the inhibition of sporulation in the macroalga, Ulva pertusa, has recently been proposed as a new ISO standard method which has several advantages over other currently employed techniques (Han and Choi, 2005; Han et al., 2007, 2008, 2009). For example, this cost and time-effective test only requires a cell plate and a small volume of water. It takes about $3 \mathrm{~h}$ to perform, following the 96-h incubation period, and requires no specialist expertise. The Ulva method demonstrated similar or, in many cases, superior sensitivity to those of other widely used bioassay methods. Furthermore, the measured end-point of the test is of ecological significant as population recruitment occurs through reproduction. Year-round testing is also possible with uni-algal Ulva plants since samples collected from the field can be easily maintained in laboratory holding tanks for between 1 and 2 months, and the laboratory culture conditions of vegetative thalli can be modified to facilitate reproduction.

The Ulva test may, therefore, be applicable to the TIE/toxicity reduction evaluation (TRE) procedures for wastewaters. The aims of the present study were two-fold: firstly, to determine the impact of wastewater effluents on the receiving water by monitoring toxicity in samples obtained on a regular basis from a wastewater treatment plant (WTP) and its adjacent stream using inhibition of reproduction in Ulva pertusa as the test endpoint, and secondly, to develop a novel TIE method using the macroalgal test for characterization, identification and confirmation of the main causative agents of toxicity in the effluents. The TIE/TRE technique using Ulva will signify a breakthrough in waste-water management technology since no such technique developed thus far is based on established ISO protocols.

\section{MATERIALS AND METHODS SAMPLE COLLECTION}

Procedures employed for the collection and analyses of water samples followed those described by Yi et al. (2009); a brief description is provided for information. Monthly water sampling was conducted from a WTP and an adjacent stream, located in Yangju, Kyunggi Do, South Korea, The WTP treats about $23,000 \mathrm{~m}^{3}$ of wastewater from textile and dyeing facilities, daily. Figure 1 is a flow diagram of the wastewater treatment process at the WTP, indicating the four wastewater collection points: raw wastewater (RW), primary effluent $(\mathrm{PE})$, secondary effluent (SE), and final effluent (FE). There were two additional points of collection from the adjacent stream water, upstream (US) and downstream (DS), at distances of approximately $50 \mathrm{~m}$ from the discharge point of the FE. Water samples were transported in acid washed/sterilized polyethylene containers on ice to the laboratory and stored at $4{ }^{\circ} \mathrm{C}$ before initiating experiments. Initial toxicity tests and water quality analyses were conducted upon arrival of the samples.

\section{CHEMICAL ANALYSIS}

A $0.45 \mu \mathrm{m}$ syringe filter was used to filter samples which were then analyzed for the following: dissolved organic carbon (Shimadzu total organic carbon analyzer, model 5000A; Kyoto, Japan), hardness and total suspended solids (TSSs) according to the "Standard Methods for the Examination of Water and Wastewater" (APHA, 1998), total residual chlorine (ThermoElectron Inc., USA model 97-70 residual chlorine analyzer), ammonia concentrations (ammonia electrode model 95-12, Thermo Electron Inc., USA), and metal concentrations (Varian inductively coupled plasma-optical emission spectrophotometer [ICP-OES], Varian Vista PRO, CA, USA). The apparatus and containers used for metal analyses were acid-cleaned before use. Standard solutions were prepared fresh and standard calibration curves $\left(r^{2}>0.995\right)$ were taken daily. A standard solution was analyzed to verify its concentration after every 12 samples, to ensure the quality of data. The precision of the data ranged from 94 to $107 \%$ and the detection limits, calculated by the method based on the standard deviations of blanks in triplicate, ranged from 4 to $14 \mu \mathrm{g} \cdot \mathrm{L}^{-1}$.

\section{TOXICITY TEST}

Ulva pertusa was collected from sites near Ahnin on the eastern coast of Korea $\left(37.4^{\circ} \mathrm{N}, 129.1^{\circ} \mathrm{E}\right)$. Immediately after transportation to the laboratory, the algae were maintained in plastic tanks with aerated artificial seawater medium prepared by dissolving 


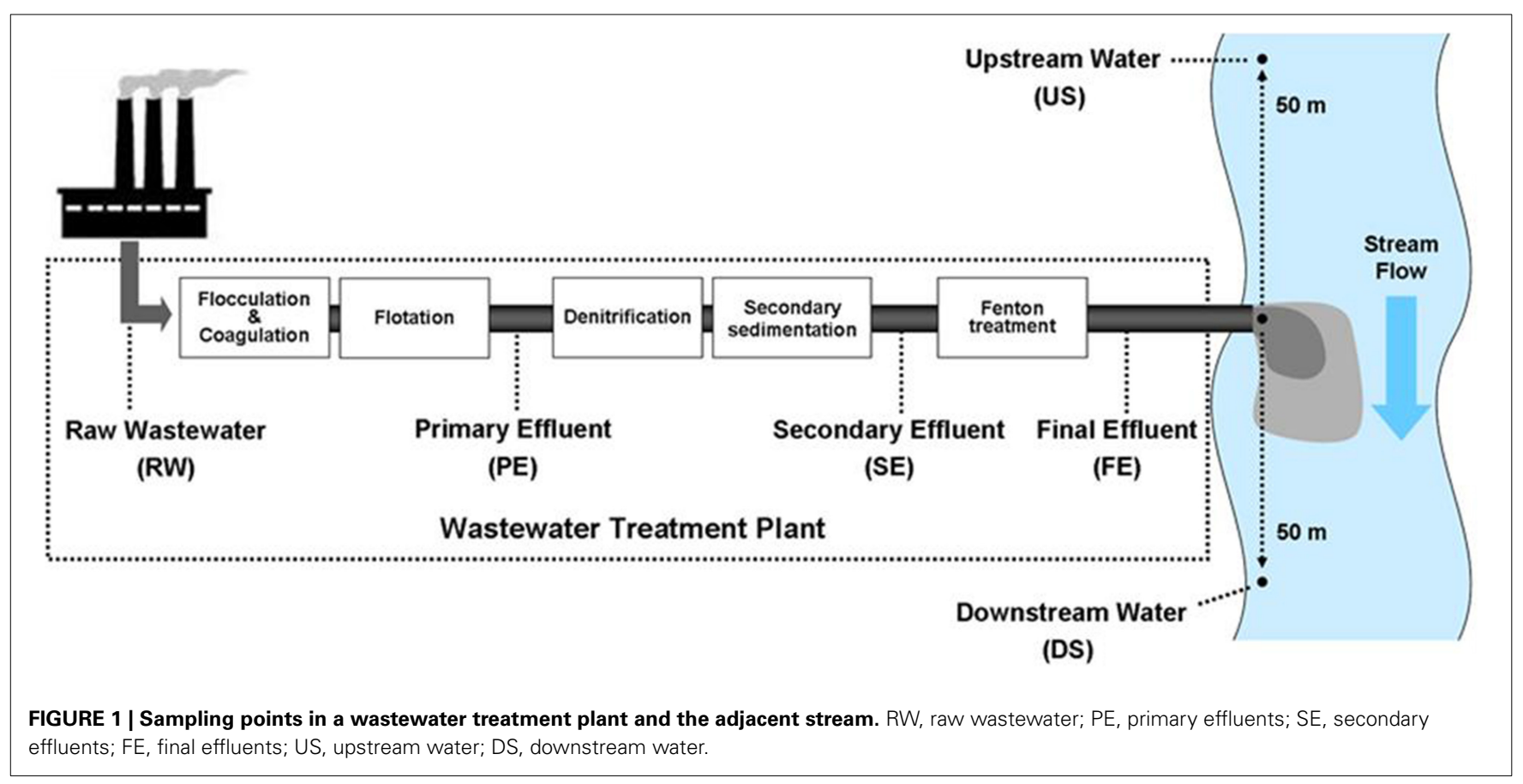

commercial sea salts (Coralife; Energy Savers, CA, USA) in deionized water to a concentration of $30 \%$ to which was added $1 \mathrm{mM} \mathrm{KNO}_{3}$ and $0.1 \mathrm{mM} \mathrm{K}_{2} \mathrm{HPO}_{4}$ as nutrients. Unialgal stock cultures were maintained at $15^{\circ} \mathrm{C}$ under $30-40 \mu \mathrm{mol}$ photons $\mathrm{m}^{-2} \cdot \mathrm{s}^{-1}$ of continuous white fluorescent light (FL400; Kum-Ho, Seoul, Korea) with a 12:12 h light-dark cycle. Disks (ø $4 \mathrm{~mm}$ ) were cut from the marginal region of the thallus and distributed to 24 -well test plates, each containing $2.5 \mathrm{~mL}$ of medium. For each toxicity test, 5 dilutions of an effluent sample and 1 control were prepared and replicated 4 times. Disks were then exposed for $96 \mathrm{~h}$ under optimal environmental conditions: photon irradiance (80-100 $\mu \mathrm{mol}$ photons $\cdot \mathrm{m}^{-2} \cdot \mathrm{s}^{-1}$ ) with $12: 12 \mathrm{~h}$ LD photoperiod, salinity $(30 \%)$ and temperature $\left(15^{\circ} \mathrm{C}\right)$, as previously determined (Han et al., 2007, 2008). The medium was not replaced during the testing period. Following exposure, disks were harvested for determination of the extent of spore release using image analysis (MV200; Samsung, Seoul, Korea) combined with microscopic observations at a $400 \times$ magnification (Axioscope; Zeiss, Berlin, Germany). The area of empty cells was measured and the percentage spore release then calculated as a proportion of empty area of the total sporulated area.

\section{TIE}

In accordance with TIE guidelines (US EPA, 1991, 1993a,b), FE samples collected in March 2008 were used in the TIE. The factors included in Phase I to characterize classes of toxicants were: baseline, test $\mathrm{pH}$ adjustment, $\mathrm{pH}$ adjustment/filtration, $\mathrm{pH}$ adjustment/C18 solid phase extraction (SPE), EDTA and sodium thiosulfate (STS) additions. Different concentrations ranging from 70 to $141.4 \mathrm{mg} \cdot \mathrm{L}^{-1}$ were used for DTA chelation tests and a concentration range of $9.48-355 \mathrm{mg} \cdot \mathrm{L}^{-1}$ was used for STS reduction tests. To further characterize toxicants, ion exchange manipulations were performed. Anion and cation exchange columns were prepared with $60 \mathrm{~mL}$ syringes filled with either anion (Amberlite IRA-410, chloride form, Aldrich, USA) or cation (Amberlite IR-120, sodium form; Aldrich, USA) exchange resins. The samples were added to both ion exchange columns in sequential order for the mixed ion exchange (anion and cation). The $\mathrm{pH}$ of the samples after each manipulation was readjusted to the initial $\mathrm{pH}$ with $\mathrm{NaOH}$ and $\mathrm{HCl}$ before conducting toxicity testing.

For the TIE phase II test, the concentrations of metals, suspected of being key toxic materials after the TIE I test, in FE samples were measured using a Varian ICP-OES (Varian Vista PRO; CA, USA). Aliquots of samples were acidified with concentrated nitric acid. From the results of the metal analyses, the toxicity of suspected toxicants was confirmed using the mass balance and spiking approaches of the phase III test. For the former approach, the concentration of a suspected metal measured in the filtered sample was added to FE samples following manipulations that reduced toxicity (e.g., ion exchange or $\mathrm{pH}$ adjustment to 11) and toxicity tests then undertaken. For the spiking approach, the same concentration of metal was added to the filtered sample and toxicity tests performed to determine if the toxicity increased linearly with the addition of the suspected toxicant.

\section{DATA ANALYSIS}

To establish statistical significance between treatments in the toxicity tests One-Way analyses of variance (ANOVA), followed by the least significance difference $(\mathrm{LSD}=\mathrm{v}(2 \times$ errorMS $/ \mathrm{n}) \times$ $\mathrm{t}_{0.05}$ ) post-hoc test at $P<0.05$, were carried out on arcsinetransformed data. Results are reported as $\mathrm{EC}_{50}$ values with $95 \%$ confidence intervals, estimated using the linear interpolation method (Toxical 5.0; Tidepool Science, CA, USA). For the purpose of comparison, $\mathrm{EC}_{50}$ values have been transformed into toxic units $\left(T U=100 / E C_{50}\right)$. 


\section{RESULTS AND DISCUSSION TOXICITY MONITORING}

The toxicity monitoring results for the WTP effluents and adjacent stream waters over the different sampling events are shown in Figure 2. There were monthly changes in the toxicity of the effluents and adjacent stream waters. The mean TUs decreased in the order of RW, PE, and SE $(13.44,2.86$, and 2.50, respectively) while the TU for FE increased to 6.12 (Table 1). It is usually expected that toxicity will decrease as wastewater undergoes further treatment, but the present observations showed significantly increased TU values of $\mathrm{FE}$, compared with $\mathrm{PE}$ and SE, until April. As Fenton processes are applied between the treatments for the SE and FE in the WTP studied it was thought that these might be associated with the increased toxicity of the FE.

It was also noted that the toxicity of DS (3.82 TU) was higher than that of US $(2.07 \mathrm{TU})$. There was a significant correlation between the toxicity of FE and DS ( $r^{2}=0.89, p<0.01$; Figure 3$)$, suggesting that effluents from the WTP were having impacts on the toxicity of DS in the neighboring stream.

TIE procedures were conducted on the March FE sample. Phase I results are shown in Figure 4. Toxicity of the FE was not altered following $\mathrm{pH}$ modifications, anion exchange or C18/SPE reduction, indicating that neither ammonia, anionic chemicals or organic compounds contributed to the observed toxicity. In contrast, adjusting the FE to $\mathrm{pH} 11$ followed by filtration and EDTA chelation, as well as cation and mixed ion exchange, completely eliminated the toxicity. This indicates that cationic compounds, such as metals which would form a hydroxide precipitate at $\mathrm{pH}$ 11 , may be responsible for toxicity.

Phase II revealed that the concentrations of 3 metals $(\mathrm{Cu}, \mathrm{Ni}$, and $\mathrm{Zn}$ ) in the $\mathrm{FE}$ samples were similar to, or greater than, the $\mathrm{EC}_{50}$ concentrations of the corresponding standard metals for $U$. pertusa (Table 2 and Figure 4). When the concentrations of each metal in the FE wastewater samples over the sampling events (except for November due to the lack of metal analysis) were plotted against the respective toxicity units, it was found that only zinc showed a statistically significant correlation with toxicity $\left(r^{2}=0.86, p<0.05\right.$; Figure 5). In addition, a substantial reduction in toxicity was observed in correspondence with the decrease in $\mathrm{Zn}$ concentration after $\mathrm{pH}$ adjustment to 11 followed by filtration, cation exchange or mixed ion exchange (Figure 4). All this evidence indicates that $\mathrm{Zn}$ was the most likely toxicant in the FE samples.
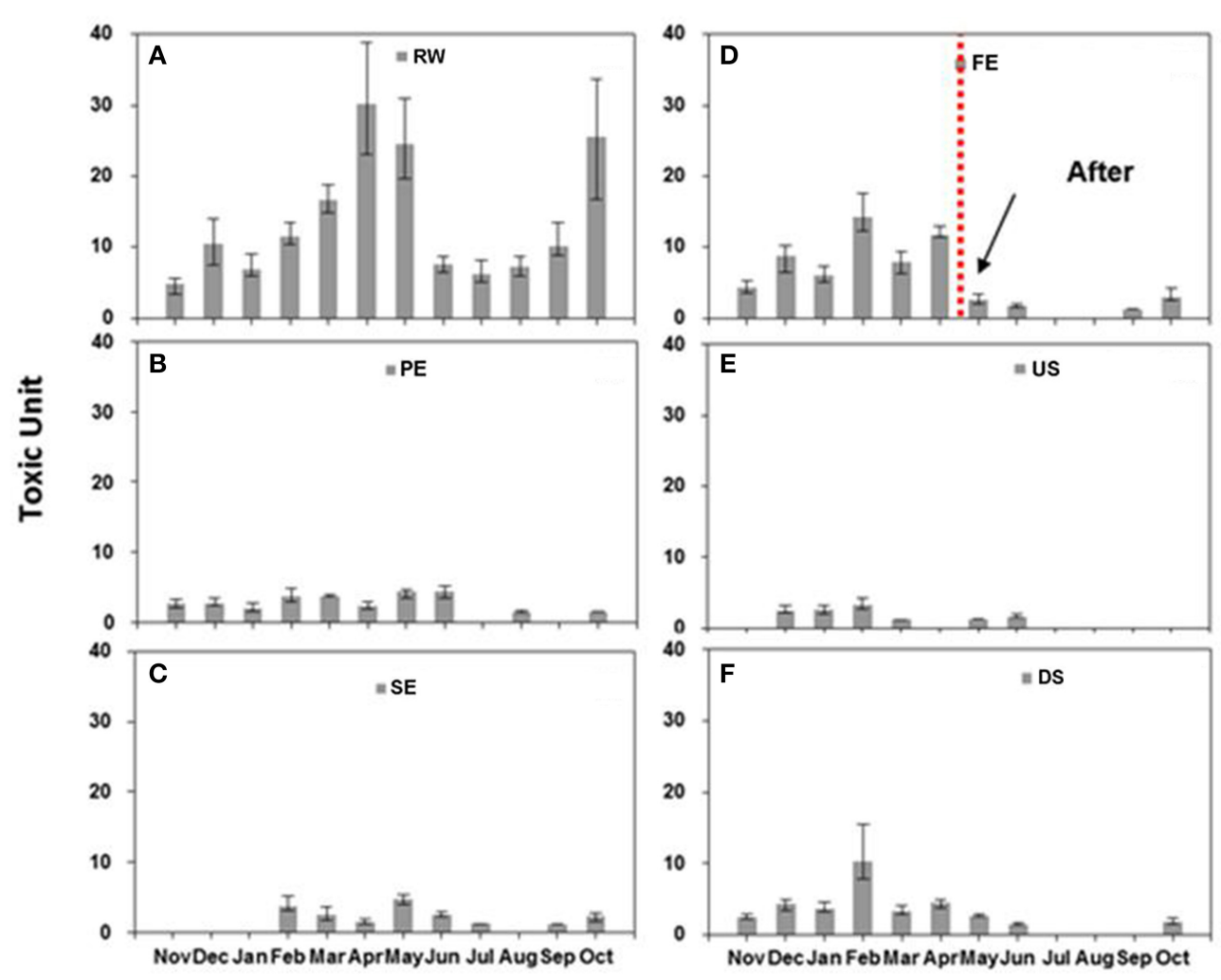

\section{Month}

FIGURE 2 | Toxicity monitoring of WTP effluents and adjacent stream waters. (A-F) indicate toxic units measured in each sampling point: (A) raw wastewater (RW); (B) primary effluents (PE); (C) secondary effluents (SE); (D) final effluents (FE); (E) upstream water
(US); (F) downstream water (DS) monthly. The error bars represent 95\% confidence intervals. The vertical line between April and May indicates the time when the Fenton reagent was changed from low to a higher quality. 
Table 1 | Mean and standard deviation of toxicity and chemical characteristics of WTP effluents and the adjacent stream water.

\begin{tabular}{|c|c|c|c|c|c|c|}
\hline & RW & PE & SE & FE & US & DS \\
\hline $\mathrm{pH}$ & $8.58 \pm 0.33$ & $8.55 \pm 0.21$ & $7.69 \pm 0.09$ & $6.96 \pm 0.10$ & $7.47 \pm 0.17$ & $7.36 \pm 0.07$ \\
\hline $\mathrm{DO}\left(\mathrm{mg} \cdot \mathrm{L}^{-1}\right)^{*}$ & $0.52 \pm 0.15$ & $0.66 \pm 0.24$ & $6.53 \pm 0.71$ & $7.74 \pm 0.66$ & $6.72 \pm 0.99$ & $7.36 \pm 0.80$ \\
\hline Ammonia (as $\mathrm{NH}_{3}$, $\mathrm{mg} \cdot \mathrm{L}^{-1}$ ) & $33.49 \pm 9.89$ & $30.96 \pm 8.91$ & $1.68 \pm 1.17$ & $2.28 \pm 1.19$ & $25.48 \pm 7.83$ & $17.50 \pm 3.97$ \\
\hline Hardness (as $\mathrm{CaCO}_{3}, \mathrm{mg} \cdot \mathrm{L}^{-1}$ ) & $103.81 \pm 36.62$ & $266.06 \pm 95.23$ & $294.29 \pm 91.02$ & $315.91 \pm 130.53$ & $300.99 \pm 92.04$ & $272.17 \pm 90.26$ \\
\hline $\mathrm{TU}(96 \mathrm{~h}) * * * * *$ & $13.44 \pm 4.92$ & $2.86 \pm 0.62$ & $2.50 \pm 0.70$ & $6.12 \pm 2.50$ & $2.07 \pm 0.47$ & $3.82 \pm 1.49$ \\
\hline
\end{tabular}

$R W$, raw wastewater; PE, primary effluents; SE, secondary effluents; FE, final effluents; US, upstream water; DS, downstream water. * Dissolved oxygen; ** ${ }^{*}$ total residual chlorine; ${ }^{* * *}$ dissolved organic carbon; ${ }^{* * *}$ total suspended solids; ${ }^{* * * * *}$ toxic unit (TU $\left.=100 / E C_{50}\right)$.

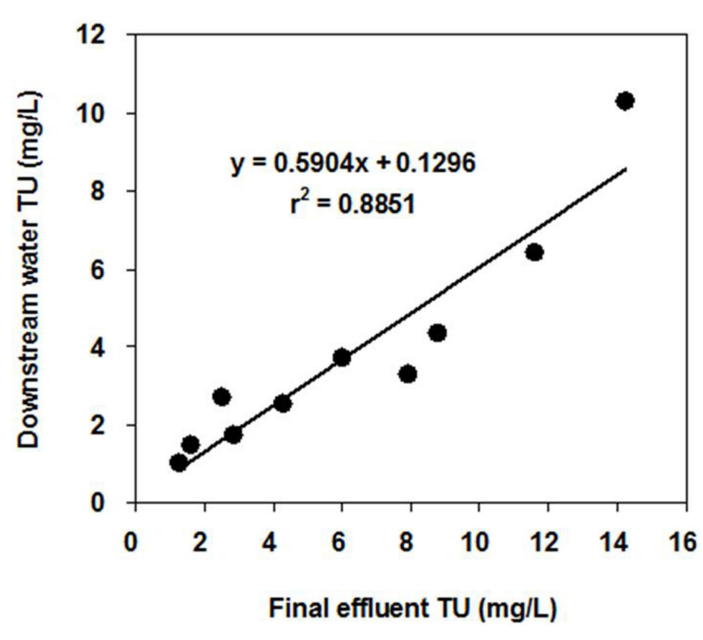

FIGURE 3 | Correlation between the toxicity of the final effluent (FE) and the toxicity of the downstream water (DS). The error bars represent $95 \%$ confidence intervals.

In order to confirm if $\mathrm{Zn}$ was the major toxicant in the $\mathrm{FE}$, spiking and mass balance studies were conducted. As shown in Figure 6, the toxicity increased about two-fold, compared with that of the filtered samples treated with $\mathrm{pH}$ modifications, anion exchange and $\mathrm{C}_{18}$ SPE reduction when $\mathrm{Zn}\left(25.0 \mathrm{mg} \cdot \mathrm{L}^{-1}\right)$ was added to the FE sample (spiking study). Similarly, the toxicity of the samples treated with cation exchange, mixed ion exchange, and $\mathrm{pH} 11$ /filtration was also recovered to that of the filtered FE sample after the addition of $25.0 \mathrm{mg} \cdot \mathrm{L}^{-1} \mathrm{Zn}$ into the samples (mass balance study). These results confirmed that $\mathrm{Zn}$ is a key toxicant affecting both the FE and DS.

\section{TOXICITY REDUCTION}

Contrary to the generally held view that toxicity of FE should decrease as treatment processes proceed we observed a higher level of toxicity in the FE than in the SE (Table 1). This implies that increased toxicity could be attributed to the chemicals added in the Fenton process during treatment of the SE (Figure 1). We found that $\mathrm{Zn}$ concentrations in the Fenton reagent (FeCl2) added to the March FE samples were significantly higher than those in the other effluent samples (Table 2). The $\mathrm{Zn}$ concentration in the reagent was $83,900 \mathrm{mg} \mathrm{L}^{-1}$. After changing the Fenton reagent to one containing a lower $\mathrm{Zn}$ content prior to the May collection, $\mathrm{Zn}$ concentrations in the FE greatly decreased from $19.52 \mathrm{mg} \cdot \mathrm{L}^{-1}$ in April to 1.91 and $0.92 \mathrm{mg} \cdot \mathrm{L}^{-1}$ in May and June, respectively. In accordance with these observations, the FE toxicity in May also decreased from 11.60 in April to $2.52 \mathrm{TU}$ in May (Figure 2, Table 3). $\mathrm{Zn}$ is therefore considered to the main contributor to the toxicity of WTP effluent at the "end of the pipe."

In the WTP studied here, Fenton treatment had been conducted in order to remove the color and chemical oxygen demand of the SE. Fenton's reagent is a mixture of ferrous iron (catalyst) and hydrogen peroxide (an oxidizing agent) and is considered to be one of the most promising oxidative techniques for the abatement of refractory and/or toxic organic pollutants in water and wastewater, and as a powerful oxidant for organic contaminants (Kang et al., 2000; Neyens and Baeyens, 2003; Kavitha and Palanivelu, 2005). However, Fenton processes have several drawbacks including: high costs, a requirement for acidic conditions, interference from substances that complex ionic Fe and the production of iron oxide sludge. Yet, despite these problems they are used for the treatment of several types of wastewaters, including those produced in dye manufacture, pulp bleaching, agricultural processing and chemical manufacture, due to the effectiveness of inducing oxidation and coagulation during the treatment processes (Stasinakis, 2008).

In the studied WTP, the Fenton reagent dosage was optimized in accordance with the wastewater flow rate (pers comm.), and therefore different doses of reagent were unlikely to be responsible for the observed variation in FE toxicity. Thus, variation in quality of the Fenton reagent was suspected. Our findings were conveyed to the management of the plant with the recommendation that the WTP should consider exchanging the currently used reagents for the Fenton process with those of higher quality. From May higher quality reagents were used and this resulted in reduced toxicity of the FE thereafter, indicating that the toxicity of the FE was caused by the presence of $\mathrm{Zn}$ in the low quality Fenton reagent. Thus, a general recommendation from this study is that higher quality chemical reagents be used for wastewater treatment as this can reduce unintended effluent toxicity. 

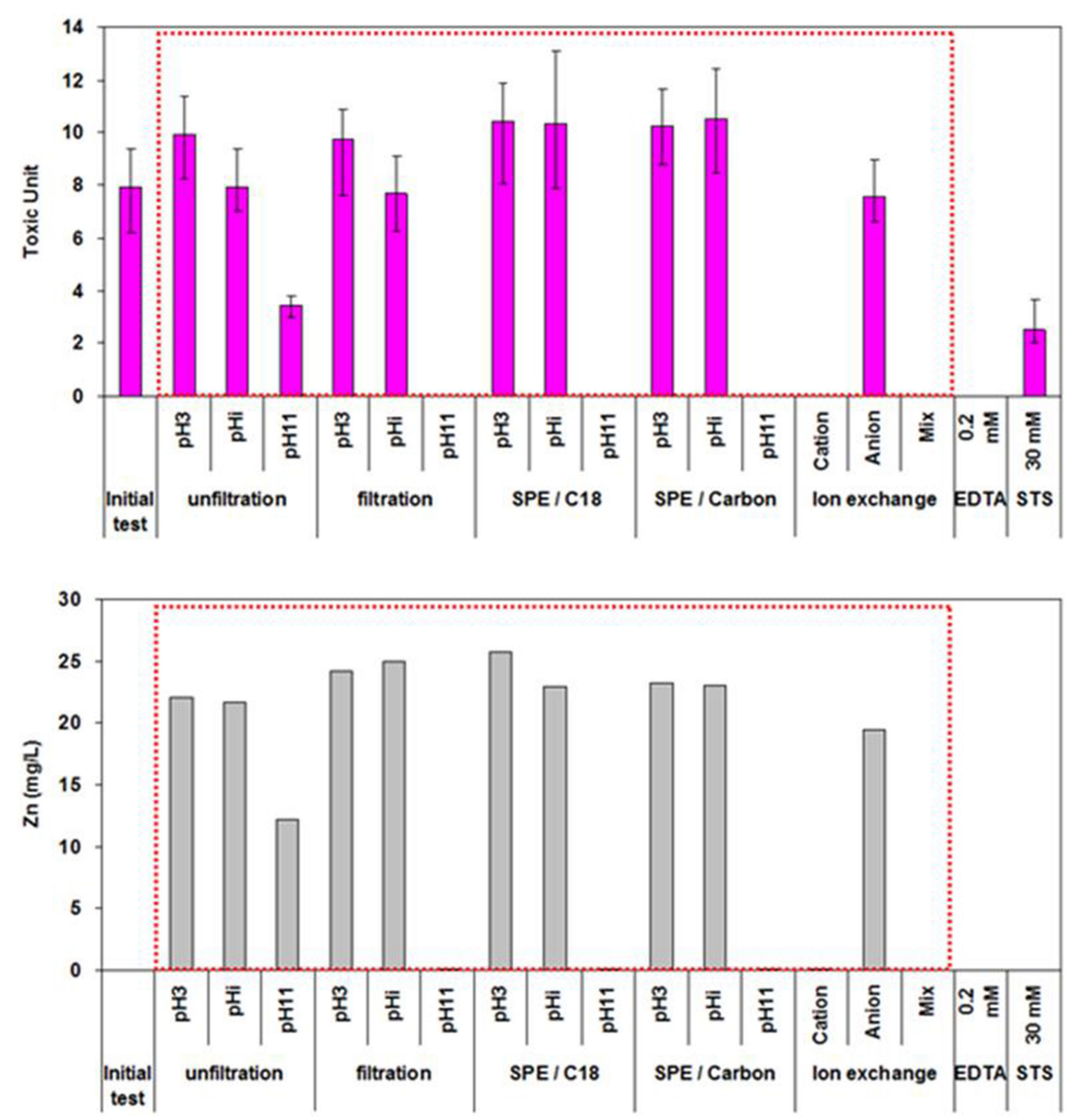

FIGURE 4 | Phase I and II toxicity characterization and identification (TIE) of final effluent (March 2008) using U. pertusa. The error bars represent $95 \%$ confidence intervals.

Table 2 | Mean and standard deviation of metal concentrations of WTP effluents and the adjacent stream water over a year.

\begin{tabular}{lccccccc}
\hline Heavy metals $\left(\mathbf{m g ~ L}^{-\mathbf{1}}\right)$ & $\mathbf{R W}$ & $\mathbf{P E}$ & $\mathbf{S E}$ & FE & US & DS & Ulva EC50s (95\% Cl) \\
\hline $\mathrm{Cd}$ & $0.024 \pm 0.020$ & $0.011 \pm 0.003$ & $0.014 \pm 0.004$ & $0.020 \pm 0.008$ & $0.032 \pm 0.013$ & $0.026 \pm 0.010$ & $0.224(0.194-0.284)$ \\
$\mathrm{Co}$ & $0.045 \pm 0.028$ & $0.017 \pm 0.012$ & $0.013 \pm 0.004$ & $0.016 \pm 0.004$ & $0.001 \pm 0.000$ & $0.005 \pm 0.002$ & $0.100(0.075-0.176)$ \\
$\mathrm{Cr}$ & $0.261 \pm 0.136$ & $0.018 \pm 0.010$ & $0.008 \pm 0.003$ & $0.006 \pm 0.002$ & $0.014 \pm 0.006$ & $0.010 \pm 0.011$ & $0.803(0.707-0.915)$ \\
$\mathrm{Cu}$ & $1.047 \pm 0.530$ & $0.028 \pm 0.013$ & $0.143 \pm 0.067$ & $0.091 \pm 0.027$ & $0.056 \pm 0.045$ & $0.061 \pm 0.040$ & $0.080(0.069-0.093)$ \\
$\mathrm{Fe}$ & $0.987 \pm 0.243$ & $0.590 \pm 0.529$ & $0.370 \pm 0.230$ & $0.105 \pm 0.046$ & $0.212 \pm 0.116$ & $0.217 \pm 0.115$ & $3.103(2.579-3.330)$ \\
$\mathrm{Mn}$ & $0.086 \pm 0.025$ & $0.099 \pm 0.042$ & $0.133 \pm 0.021$ & $0.419 \pm 0.042$ & $0.311 \pm 0.099$ & $0.354 \pm 0.088$ & $1.430(1.243-1.591)$ \\
$\mathrm{Ni}$ & $0.857 \pm 0.390$ & $0.518 \pm 0.364$ & $0.348 \pm 0.070$ & $0.373 \pm 0.072$ & $0.058 \pm 0.022$ & $0.173 \pm 0.060$ & $0.306(0.271-0.344)$ \\
$\mathrm{Zn}$ & $1.854 \pm 1.269$ & $0.792 \pm 0.556$ & $0.695 \pm 0.372$ & $\mathbf{8 . 7 9 7} \pm \mathbf{5 . 5 0 8}$ & $0.126 \pm 0.067$ & $2.855 \pm 1.444$ & $0.794(0.546-1.252)$
\end{tabular}

$R W$, raw wastewater; $P E$, primary effluents; $S E$, secondary effluents; FE, final effluents; US, upstream water; DS, downstream water.

\section{CONCLUSION}

When an effluent has been identified as toxic to aquatic organisms, a traditional step to take is to chemically analyze a sample of wastewater based on so-called "priority pollutants." However, it has become evident that chemical-specific approaches for controlling toxicity are of limited value, because many effluents, of various origins, contain numerous toxic chemicals, the effects of which may not be easily assessed by routine chemical analyses. For instance, the bioavailability of a toxicant may be low even when the measured concentrations are high or conversely, pollutants may have high toxicity even when present at low concentrations. To overcome such problems TIE procedures were 
Table 3 | Toxicity and $\mathrm{Zn}$ concentrations of wastewater treatment plant final effluents.

\begin{tabular}{lccc}
\hline Month & $\mathbf{Z n}\left(\mathbf{m g ~ L}^{-\mathbf{1}}\right)$ & $\boldsymbol{T U}(\mathbf{9 6} \mathbf{h})$ & $\boldsymbol{C V}(\mathbf{\%})$ \\
\hline November & - & $\mathbf{4 . 3 0}(\mathbf{3 . 4 8 - 5 . 1 8 )}$ & 6.5 \\
December & $\mathbf{1 0 . 0 2 9}$ & $\mathbf{8 . 7 9}(\mathbf{6 . 4 7 - 1 0 . 3 0 )}$ & 8.2 \\
January & $\mathbf{2 0 . 1 2 0}$ & $\mathbf{6 . 0 0}(\mathbf{5 . 0 7 - 7 . 3 8 )}$ & 6.7 \\
February & $\mathbf{1 6 . 7 0 0}$ & $\mathbf{1 4 . 2 3}(\mathbf{1 2 . 2 2}-\mathbf{1 7 . 6 2})$ & 5.7 \\
March & $\mathbf{2 5 . 0 5 0}$ & $\mathbf{7 . 9 3}(\mathbf{6 . 2 2}-\mathbf{9 . 3 6})$ & 11.9 \\
April & $\mathbf{1 9 . 5 2 0}$ & $\mathbf{1 1 . 6 0 ( 1 1 . 4 0 - 1 3 . 0 0 )}$ & 4.5 \\
May & 1.907 & $2.52(2.03-3.32)$ & 12.6 \\
June & 0.915 & $1.65(1.48-2.00)$ & 7.9 \\
July & 0.758 & $<1.00$ & - \\
August & 0.264 & $<1.00$ & - \\
September & 0.729 & 1.29 & - \\
October & 0.777 & $2.87(2.57-4.27)$ & 9.9
\end{tabular}

developed by the USEPA, and have been employed to characterize, identify and confirm the causes of toxicity in toxic complex effluents.

The TIE developed here, based on inhibition of sporulation in $U$. pertusa, enabled the toxicity of FEs of the WTP to be tracked and for $\mathrm{Zn}$, originating from a reagent used for Fenton treatment, to be successfully identified as the key toxicant. We also conclude that reagents used in wastewater treatment procedures, such as the Fenton process, should be evaluated for purity to avoid inadvertent toxicity. Therefore, the TIE process employing U. pertusa has been shown to be a useful method for identifying toxicants in a wastewater effluent, and provided a cost-effective control strategy entailing only a minor change in an existing reagent. Furthermore, it was notable that FE toxicity varied between sampling events and that toxicity of the DS was significantly affected by the input of toxic effluent. Thus, for better assessment the toxicity of effluents, as well as adjacent streams, should be monitored over longer time periods since a single sampling event may not necessarily predict toxicity due to inherent variability. In this study, only acute toxicity of effluents was assessed in accordance with new Korean legislation (M.O.E. Korea, 2007). However, we propose that longer term chronic effects of wastewater effluents should be monitored to adequately evaluate the impacts of a persistent discharge of low levels of toxic chemicals to receiving water bodies. The TIE results may be useful for regulatory agencies to formulate more precise and practical measures to protect aquatic environments against the hazards of wastewater effluents. The same TIE could also be applied as an effective tool for the assessment of other types of effluent toxicity. Finally, we have shown that the use of the TIE based on Ulva spore release could provide companies that discharge industrial wastewater with a practical and economical methodology that allows for the identification of pollution sources in effluents, and for subsequent toxicity reduction. For the use of marine macroalga for the toxicity assessment of non-saline/fresh waste water, however, the addition of salts to adjust the salinity of test samples was required prior to toxicity testing. It is well known that toxicity changes depending on the salinity of the medium (Latala and Surosz, 1998). Therefore, the toxicity limits of $U$. pertusa determined in normal marine

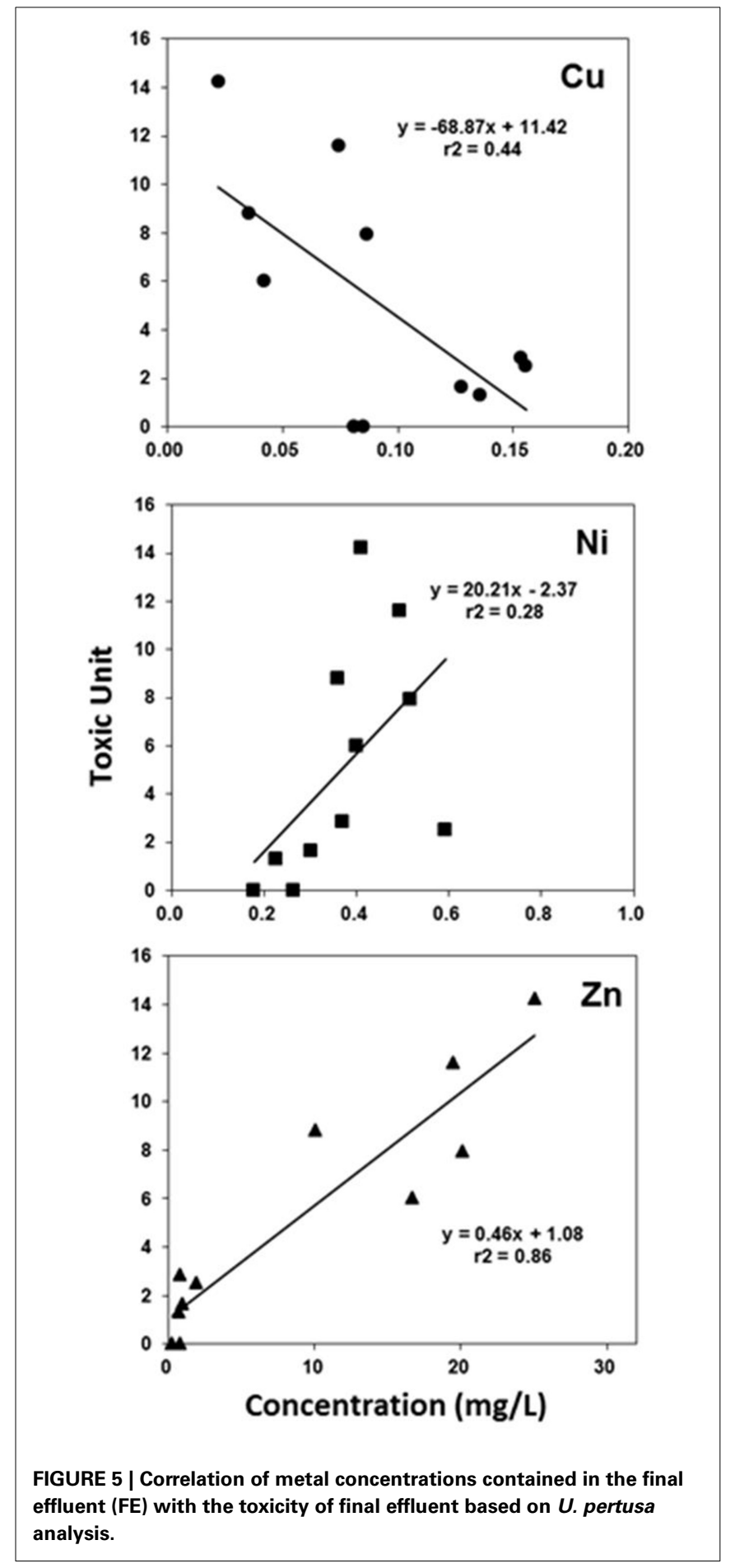

conditions may not reflect those prevailing in freshwaters. In a recent study, we have found that $U$. pertusa is likely to be more susceptible to low levels of pollution in estuaries compared with coastal waters (Oh et al., 2012). If there is any sign of toxicity in salinity-adjusted water samples, it would indicate that the original freshwater samples would have been more toxic, thus making Ulva pertusa an early warning indicator of freshwater pollution. 


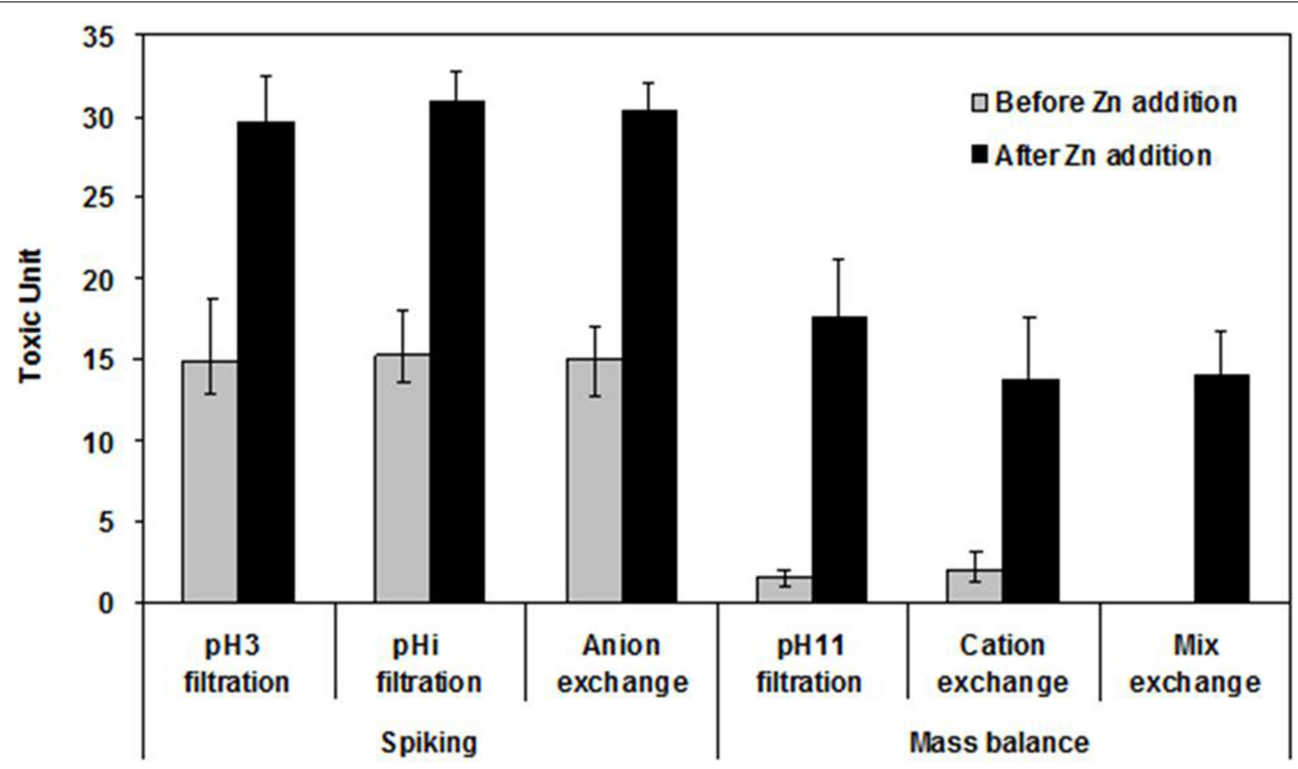

FIGURE 6 | Phase III toxicity confirmation by spiking and mass balance treatments. The concentration of added $\mathrm{Zn}$ was $25.05 \mathrm{mg} \cdot \mathrm{L}^{-1}$ which was the concentration found in the final effluent.

\section{ACKNOWLEDGMENT}

This work was supported by Incheon National University (International Cooperative Research Grant).

\section{REFERENCES}

Ahlf, W., Hollert, H., Neumann-Hensel, H., and Ricking, M. (2002). A guidance for the assessment and evaluation of sediment quality: a German approach based on ecotoxicological and chemical measurements. J. Soils Sediments 2, 37-42. doi: 10.1007/BF02991249

Ankley, G. T., Schubauer-Berigan, M. K., and Hoke, R. A. (1992). Use of toxicity identification evaluation techniques to identify dredged material disposal options: a proposed approach. Environ. Manage. 16, 1-6. doi: 10.1007/BF02393904

APHA (American Public Health Association). (1998). Standard Methods for the Examination of Water and Wastewater, 20th Edn. Washington, DC.

Bidwell, J. R., Wheeler, K. W., and Burridge, T. R. (1998). Toxicant effects on the zoospore stage of the marine macroalga Ecklonia radiata (Phaeophyta: Laminariales). Mar. Ecol. Prog. Ser. 163, 259-265. doi: 10.3354/meps 163259

Chu, K. W., and Chow, K. L. (2002). Synergistic toxicity of multiple heavy metals is revealed by a biological assay using a nematode and its transgenic derivative. Aquat. Toxicol. 61, 53-64. doi: 10.1016/S0166-445X(02)00017-6

Erten-Unal, M., Gelderloos, A. B., and Hunghes, J. S. (1998). A toxicity reduction evaluation for an oily waste treatment plant exhibiting episodic effluent toxicity. Sci. Total Environ. 218, 141-152. doi: 10.1016/S0048-9697(98)00208-3

Han, T., and Choi, G.-W. (2005). A novel marine algal toxicity bioassay based on sporulation inhibition in the green macroalga Ulva pertusa (Chlorophyta). Aquat. Toxicol. 75, 202-212. doi: 10.1016/j.aquatox.2005.08.003

Han, T., Han, Y.-S., Park, C. Y., Jun, Y. S., Kwon, M. J., Kang, S.-H., et al. (2008). Spore release by the green alga Ulva: a quantitative assay to evaluate aquatic toxicants. Environ. Pollut. 153, 699-705. doi: 10.1016/j.envpol.2007.09.001

Han, Y.-S., Brown, M. T., Park, G. S., and Han, T. (2007). Evaluating aquatic toxicity by visual inspection of thallus color in the green macroalga Ulva: testing a novel bioassay. Environ. Sci. Technol. 41, 3667-3671. doi: 10.1021/es062158a

Han, Y.-S., Kumar, A. S., and Han, T. (2009). Comparison of metal toxicity bioassays based on inhibition of sporulation and spore release in Ulva pertusa. Toxicol. Environ. Health Sci. 1, 24-31. doi: 10.1007/BF03216460

Hogan, A. C., Stauber, J. L., Pablo, F., Adams, M. S., and Lim, R. P. (2005). The development of marine toxicity identification evaluation (TIE) procedures using the unicellular alga Nitzchina closterium. Arch. Environ. Contam. Toxicol. 48, 433-443. doi: 10.1007/s00244-003-0137-y

Jin, H., Yang, X., Yin, D., and Yu, H. (1999). A case study on identifying the toxicant in effluent discharged from a chemical plant. Mar. Pollut. Bull. 39, 122-125. doi: 10.1016/S0025-326X(99)00118-6

Jo, H. J., Park, E. J., Cho, K., Kim, E. H., and Jung, J. (2008). Toxicity identification and reduction of wastewaters from a pigment manufacturing factory. Chemosphere 70, 949-957. doi: 10.1016/j.chemosphere.2007.08.018

Kang, S. F., Liao, C. H., and Po, S. T. (2000). Decolorization of textile wastewater by photo-Fenton oxidation technology. Chemosphere 41, 1287-1297. doi: 10.1016/S0045-6535(99)00524-X

Kavitha, V., and Palanivelu, K. (2005). Destruction of cresols by Fenton oxidation process. Water Res. 39, 3062-3072. doi: 10.1016/j.watres.2005.05.011

Latala, A., and Surosz, W. (1998). The effect of salinity on toxic influence of heavy metals towards planktonic green algae. Biologia 53, 547-555.

M.O.E. Korea. (2007). Introduction of the Whole Effluent Toxicity (WET) Criteria for Industrial Wastewater from 2011. Seoul: Ministry of Environment.

Nedeau, E. J., Merritt, R. W., and Kaufman, M. G. (2003). The effect of an industrial effluent on an urban stream benthic community: water quality vs. habitat quality. Environ. Pollut. 123, 1-13. doi: 10.1016/S0269-7491(02)00363-9

Neyens, E., and Baeyens, J. (2003). A review of classic Fenton's peroxidation as an advanced oxidation technique. J. Hazar. Mater. B98, 33-58. doi: 10.1016/S03043894(02)00282-0

Ntengwe, F. W., and Maseka, K. K. (2006). The impact of effluents containing zinc and nickel metals on stream and river water bodies: the case of Chambishi and Mwambashi streams in Zambia. Phys. Chem. Earth. 31, 814-820. doi: 10.1016/j.pce.2006.08.027

Oh, J., Choi, E.-M., Han, Y.-S., Yoon, J.-H., Park, A., Jin, K., et al. (2012). Influence of salinity on metal toxicity to Ulva pertusa. ToxEHS 4, 9-13. doi: 10.1007/ s13530-011-0107-0

Park, E. J., Jo, H. J., Kim, H. J., Cho, K., and Jung, J. (2008). Examination of effects of gamma-ray treatment on wastewater toxicity from a rubber products factory. J. Radioanal. Nucl. Chem. 277, 619-624. doi: 10.1007/s10967-0077094-2

Pelletier, M. C., Ho, K. T., Cantwell, M., Kuhn-Hines, A., Jayaraman, S., and Burgess, R. M. (2001). Use of Ulva lactuca to identify ammonia toxicity in marine and estuarine sediments. Environ. Toxicol. Chem. 20, 2852-2859. doi: $10.1002 /$ etc. 5620201227

Stasinakis, A. S. (2008). Use of selected advanced oxidation processes (AOPs) for wastewater treatment-a mini review. Global NEST J. 10, 376-385. 
US EPA (United States Environmental Protection Agency). (1991). Methods for Aquatic Toxicity Identification Evaluations: Phase I Toxicity Characterization Procedures. Washington, DC: EPA 600/6-91/003.

US EPA (United States Environmental Protection Agency). (1993a). Methods for Aquatic Toxicity Identifications Evaluations: Phase II. Toxicity Identification Procedures for Samples Exhibiting Acute and Chronic Toxicity. Washington, DC: EPA/600/R-92/080.

US EPA (United States Environmental Protection Agency). (1993b). Methods for Aquatic Toxicity Identifications Evaluations: Phase III. Toxicity Confirmation Procedures for Samples Exhibiting Acute and Chronic Toxicity. Washington, DC: EPA/600/R-92/081.

Yi, X., Kim, E., Jo, H.-J., Schlenk, D., and Jung, J. (2009). A toxicity monitoring study on identification and reduction of toxicants from a wastewater treatment plant, Ecotoxicol. Environ. Saf. 72, 1919-1924. doi: 10.1016/j.ecoenv.2009. 04.012

Yu, H., Cheng, J., Cui, Y., Shang, H., Ding, Z., and Jin, H. (2004). Application of toxicity identification evaluation procedures on wastewaters and sludge from a municipal sewage treatment works with industrial inputs. Ecotoxicol. Environ. Saf. 57, 426-430. doi: 10.1016/j.ecoenv.2003.08.024
Conflict of Interest Statement: The authors declare that the research was conducted in the absence of any commercial or financial relationships that could be construed as a potential conflict of interest.

Received: 28 July 2014; paper pending published: 03 September 2014; accepted: 08 January 2015; published online: 03 March 2015.

Citation: Kim Y-J, Han Y-S, Kim E, Jung J, Kim S-H, Yoo S-J, Shin G-S, Oh J, Park A, Choi H, Kim M-S, Brown MT and Han T (2015) Application of the Ulva pertusa bioassay for a toxicity identification evaluation and reduction of effluent from a wastewater treatment plant. Front. Environ. Sci. 3:2. doi: 10.3389/fenvs.2015.00002 This article was submitted to Environmental Toxicology, a section of the journal Frontiers in Environmental Science.

Copyright @ 2015 Kim, Han, Kim, Jung, Kim, Yoo, Shin, Oh, Park, Choi, Kim, Brown and Han. This is an open-access article distributed under the terms of the Creative Commons Attribution License (CC BY). The use, distribution or reproduction in other forums is permitted, provided the original author $(s)$ or licensor are credited and that the original publication in this journal is cited, in accordance with accepted academic practice. No use, distribution or reproduction is permitted which does not comply with these terms. 